\title{
Effect of Post-Deposition Annealing on the Optical and Mechanical Properties of Amorphous Tungsten Oxynitride Thin Films
}

\author{
O. R. Nunez ${ }^{1}$, A. J. Moreno Tarango ${ }^{1}$, K. Hossain ${ }^{2}$ andC.V. Ramana ${ }^{1 *}$ \\ ${ }^{1}$ Department of Mechanical Engineering, University of Texas at El Paso, \\ El Paso, Texas 79968, USA \\ ${ }^{2}$ Amethyst Research Inc., 123 Case Circle, Ardmore, Oklahoma 73401, USA
}

* Author to whom correspondence should be addressed; Email: rvchintalapalle@utep.edu 


\begin{abstract}
The effect of post-deposition thermal treatment on the optical and mechanical properties of WO-N thin films is reported. W-O-N thin films were deposited onto silicon (100) and quartz substrates utilizing direct current (DC) sputtering under the variable flow of reactive gas mixture. Post-deposition annealing was performed at a temperature $\left(\mathrm{T}_{\mathrm{a}}\right)$ of $400{ }^{\circ} \mathrm{C}$ under inert (argon) and oxygen (air) atmosphere. For annealing in an inert atmosphere, spectroscopic ellipsometry (SE) revealed changes to the dispersion profiles and magnitudes of the index of refraction $(n)$ and extinction coefficient $(k)$ as a result of thermal treatment. X-ray photoelectron spectroscopy (XPS) measurements revealed the loss ofboth nitrogen and oxygen during the annealing process in an inert atmosphere while the samples remain amorphous as evidenced in X-ray diffraction measurements. The chemical changes correlate with the changes seen in the optical constants for annealed W-O-N films. Furthermore, the physical changes during post thermal treatment probed by calculating the film-density using the Lorentz-Lorenz relation indicate a decrease in density that supports the changesin chemical composition and optical properties. Density values for annealed W-O-N films vary in the range $\sim 9-12 \mathrm{~g} / \mathrm{cm}^{3}$, the low-to-high end of density values are noted for low and high values of nitrogen flow rate, respectively, employed during deposition. Mechanical properties of $\mathrm{W}-\mathrm{O}-\mathrm{N}$ films were demonstrated a drastic improvement as a result of post thermal treatment. The hardness values generally were improved but the W-O-N films annealed in air showed the significant improvement, up $\mathrm{o} \sim 10$ GPa. XRD measurementsindicated the amorphous-to-crystalline transition with $\mathrm{m}-\mathrm{WO}_{3}$ phase as dominant component for samples annealed in an air due to the abundance of oxygen absorbed during annealing.
\end{abstract}


Keywords: Tungsten Oxynitride; Thin Films, Nano-indentation; Mechanical Properties; Optical Constants

\section{Introduction}

Transition metal oxides (TMOs), which are well known for their diversity in crystal structure, optical properties, and electronic behavior, have been the subject of intense research for their utilization in modern optical and electro-optical device technologies. Tungsten oxide $\left(\mathrm{WO}_{3}\right)$, one among the TMOs, is categorized as a wide band gap semiconductor with exemplary physical and chemical stability [1-15]. With a band gap $3.0 \mathrm{eV}[1-10], \mathrm{WO}_{3}$ thin films and nanostructures have the ability to use a wide portion of electromagnetic spectrum with a characteristic high absorption extending from the blue part of the visible spectrum to the ultraviolet region [7-12]. $\mathrm{WO}_{3}$ is also recognized as a "chromogenic" material. Combined optical and electrical properties allowed $\mathrm{WO}_{3}$ to be applied in a wide range of energy related applications such as energy efficient windows, water splitting technology for hydrogen production, photocatalysis and solar cells [4-9, 12-15].

The mechanical properties of $\mathrm{WO}_{3}$ are also quite important while the material was primarily sought for application in the fields of optics, optoelectronics and photovoltaics. For instance, $\mathrm{WO}_{3}$ has been studied for intended application as a material with wear resistance in highly oxidative environments [16-18]. The oxidation resistance of $\mathrm{WO}_{3}$, especially when compared to tungsten nitride [17-18], is the primary reason for considering this material for such applications.On the other hand, well known hard coatings based on tungsten nitride (W-N) are often studied for use aswear resistant hard coatings for industrial applications [18-23]. W-N thin films display hardness values of 28-40 GPa[19-21], much greater than the values that can be obtained from $\mathrm{WO}_{3}$ which are typically in the range of 7-25 $\mathrm{GPa}$ [16-18]. Even though 
mechanical behavior for the $\mathrm{W}-\mathrm{N}$ is favorable, low oxidation resistance is detrimental to the wear resistance of hard coatings in high temperature, oxygen rich environments.

The focus of the present work is towards tungsten oxynitride (W-O-N) thin films. Note that the transition metal oxynitride materials, which can be represented chemically by $\mathrm{MO}_{\mathrm{x}} \mathrm{N}_{\mathrm{y}}$ or $\mathrm{M}-\mathrm{O}-\mathrm{N}$, are receiving considerable interest in recent years due to the fact that the advantage of the mechanical properties of transition metal nitrides and the optical and electro-optical properties of transition metal oxides combined. For $\mathrm{WO}_{3}$, anion and cation doping has recently gained much interest in order to design materials with the ability to tune optical and electrical properties. By controlling the nitrogen chemistry and composition,tungsten oxynitride (W-O-N) thin films provide a means to obtain tunable properties. By incorporating nitrogen into $\mathrm{WO}_{3}$, band gap values are tuned in order to extend absorption to longer wavelengths; improving photoelectrochemical performance for water splitting by reducing charge recombination and enhanced light absorption [24].Along with the ability to tune desired properties, W-O-N with tailored composition combine the traditional advantages of $\mathrm{WO}_{3}$ with those of $\mathrm{W}-\mathrm{N}$ resulting in a set of materials with high hardness, oxidation resistance and thermal stability at elevated temperatures. Whileeffortsexist in the literature to characterize the micro-structure, chemical composition, electrochromic, optical properties and mechanical behavior of $\mathrm{W}-\mathrm{O}-\mathrm{N}$ thin films [24-33], studies focused towards fundamental understanding of the effect of post-deposition thermal treatment arescarce [34-38].Furthermore, while results that have been published for W-O-N films regarding thermal treatment are not comprehensive,such a deeper understanding of the effect of thermal treatment and conclusive results can provide insightsinto the expected behavior of transition metal nitrides and oxynitrides in general. Experiments involving Zn-O-Nand Ta-O-N 
have revealed that the annealing process hassome effect on the optical properties of metal oxynitrides, depending on the temperature and processing atmosphere employed[39-40].

In this paper, we investigate and report on the effect of thermal annealing in both an inert atmosphere and an open atmosphere(air) on the optical and mechanical properties of W-O-N films. The chemical composition, microstructure, physical characteristics, mechanical behavior and optical properties of annealed W-O-N thin films deposited under variable nitrogen content are studied in detail to derive a better understanding of the post-deposition thermal treatment.Using the results obtained, it is demonstrated that both the index of refraction (n) and extinction coefficient $(\mathrm{k})$ can be tuned by the post-deposition annealing while controlling the hardness and Young's modulus of the W-O-N films.

\section{Experimental}

\subsection{Fabrication}

W-O-N thin films were fabricatedusing direct current (DC) sputter-deposition. The deposition was made onto silicon (Si) (100) and quartz substrates. Before introducing into the vacuum chamber, substrates were cleaned by the standard RCA (Radio Corporation of America) methodology and dried with nitrogen. A tungsten (W) metal target with a 2" diameter and $99.95 \%$ purity was employed for reactive sputtering of the thin films. The vacuum chamber was evacuated to a base pressure $\sim 3 \times 10^{-7}$ Torr and $20 \mathrm{sccm}$ of argon was subsequently introduced into the chamber. In order to ignite the plasma $100 \mathrm{~W}$ of power was supplied to the sputtering gun, positioned $80 \mathrm{~mm}$ from the substrates, by an Advanced Energy MDX 500 DC power supply. Pre-sputtering of the target was performed for 10 minutes before each deposition in order to remove any contaminants. For the fabrication of W-O-N thin films, reactive deposition 
required the use of oxygen $\left(\mathrm{O}_{2}\right)$ and nitrogen $\left(\mathrm{N}_{2}\right)$ along with argon $(\mathrm{Ar})$ during deposition. The total flow of gases for each deposition was kept at a constant $40 \mathrm{sccm}$. With Ar flow kept at 20 sccm, the remaining ratio of $\mathrm{O}_{2}$ to $\mathrm{N}_{2}$ was adjusted prior to each deposition in order to understand the effect of nitrogen content on the optical and mechanical properties. The working pressure for sputtering was kept at 10 mTorr with a pumping speed of $50 \mathrm{~L} / \mathrm{s}$. Each deposition was performed at room temperature $\left(25^{\circ} \mathrm{C}\right)$ and for the appropriate period of time to reach a thickness of $\sim 100 \mathrm{~nm}$ as measured,in situ,by an ellipsometer.

In order to investigate the effect of post thermal treatment on $\mathrm{W}-\mathrm{O}-\mathrm{N}$ thin films the samples were annealed in different atmospheres and temperatures. Two sets of W-O-N thin films, deposited onto Si substrates, were annealed at a temperature of $400{ }^{\circ} \mathrm{C}$ for 1 hour. The first set of samples was annealed in an inert atmosphere by placing the thin films in a tube furnace that was specially fitted so that Ar was continuously flowedat a constant rate through the furnace. The second set of samples was annealed in an open atmosphere, requiring only a conventional furnace set up. A third group of W-O-N thin films, deposited onto quartz substrates, was also annealed in an inert atmosphere of Ar but at a temperature of $400^{\circ} \mathrm{C}$ for $\mathbf{1}$ hour. All annealing was performed with a ramp up time of 30 minutes and the samples were allowed to cool to room temperature after the target time was reached without external cooling. A summary of the postdeposition thermal treatment performed is presented in Table 1.

\subsection{Characterization}

Chemical, structural, optical and mechanical properties of annealed W-O-N thin films were investigated using an array of analytical techniques. In order to investigate any losses of nitrogen or oxygen during the annealing process data was gathered utilizing an X-ray 
photoelectron spectroscopy (XPS) system for films grown on $\mathrm{S}$ i substrates. Concentration determination was performed using Gaussian-Lorentzian line shapes with Shirley backgroundsubtraction in order to fit high energy resolution spectra and determine the peak areas.However, XPS analyses were performed on only the as-deposited W-O-N films and those films thermally treated with a f low of Ar gas. Rutherford backscattering spectrometry (RBS) measurements were also performed on those as-deposited and annealed W-O-N samples to further understand thermally induced changes (if, any) in the chemical composition. Coupled with XPS, RBS measurements were helpful in probing the changes upon thermal annealing, especially under Ar flow. An incident ion probe containing $1.5 \mathrm{MeV}^{4} \mathrm{He}^{+}$with a normal incident to the sample was used. The backscattered ions were detected using a silicon barrier detector at a scattering angle of $150^{\circ}$. Composition profiles were determined by comparing SIMNRA computer simulations $[41,42]$ of the spectra with the experimental data.

X-ray diffraction (XRD) measurements were performed using a Bruker D8 Advance xray diffractometer. Since the W-O-N thin films only had a thickness of $\sim 100 \mathrm{~nm}$ it was deemed beneficial to perform grazing incidence X-ray diffraction (GIXRD) in order to avoid substrate interaction. Measurements were performed ex situ, at room temperature, for all of the samples deposited on Si substrates. GIXRD patterns were recorded using $\mathrm{Cu} \mathrm{K} \alpha$ radiation ( $\lambda=1.54056$ $\AA$ ), at a voltage of $40 \mathrm{kV}$ to generate the X-rays. Grazing incidence was kept at $2^{\circ}$ for the X-ray beam while the detector was free to movie in the plane of incidence in the "detector scan" mode. Scanning was performed in a $2 \theta$ range of $20-50^{\circ}$ with a step size and scan speed of $0.05^{\circ}(2 \theta)$ and $5 \%$ min, respectively. 
Optical characterization of W-O-N thin films annealed with a flow of Ar was performed utilizing spectroscopic ellipsometry (SE) and spectrophotometric measurements. SE measurements were done ex-situ, on samples grown on Si substrates, employing a J. A. Woollam VVASE spectroscopic ellipsometer and performed at wavelengths of $200 \mathrm{t} \mathrm{o} 1500 \mathrm{~nm}$. Measurements were taken at a step size of $2 \mathrm{~nm}$ and at angles of incidence of $65^{\circ}, 70^{\circ}$, and $75^{\circ}$, near the Brewster's angle of silicon. Analysis of the SE data was completed by commercially available WVASE32 software [43]. The optical transmittance of W-O-N films deposited on quartz substrates was investigated using aCary $5000 \mathrm{U}$ V-VIS-NR double-beam spectrophotometer.

Mechanical characterization of the hardness and reduced elastic modulus was performed for allsamples grown on Si substrates. U tilizing a Hysitron TI 750 TriboIndenter, nanoindentation experiments were performed with a Berkovich tip with a $396 \mathrm{~nm}$ radius of curvature. Load control nano-indentation was performed in order to obtain loading and unloading curves

for each experiment. A maximum load of $100 \mu \mathrm{N}$ was used to penetrate the films between 10 $\mathrm{nm}$ and $20 \mathrm{~nm}$, depending on the mechanical characteristics of the respective sample. F or improved reliability of the mechanical characterization each sample was loaded and unloaded at 12 separate positions and the results averaged.

\section{Results}

Annealed W-O-N films showedsignificant changes in structural, chemical, physical, mechanical and optical properties when compared to those of as-deposited W-O-N thin films. Optical constants for $\mathrm{W}-\mathrm{O}-\mathrm{N}$ thin films annealed at $400{ }^{\circ} \mathrm{C}$, for 1 hour in an inert atmosphere were analyzed using SE data. Ellipsometric parameters, $\Psi$ (azimuth) and $\Delta$ (phase change) are 
obtained measuring the relative changes in both phase and amplitude of linearly polarized light reflected from the sample. The spectral dependencies of SE parameters, $\Psi$ and $\Delta$, are fitted using appropriate models to acquire the thickness and optical constants, i.e., the index of refractive $(n)$ and extinction coefficient $(k)$ of the films $[\mathbf{4 4 , 4 5}]$. Two Gaussian oscillators were applied to fit the spectral dependencies of SE parameters. Results obtained on the dispersion profiles of both $n$ and kare shown in Figures 1 and 2, respectively. It can be observed that both the dispersion profiles of $n$ and $k$ display peaks at shorter wavelengths. After the observed peaks, values for both $n$ and $k$ decrease and undergo tailing behavior at longer wavelengths. This behavior is an indicative of changes to both physical and electro-optical properties as a result of post-deposition thermal treatment when compared to typical dispersion curves of W-O-N thin films [28-30]. Figure 3 presents the optical constants of annealed W-O-N thin films at $633 \mathrm{~nm}$ compared to values obtained for as-deposited films i.e., prior to thermal treatment. Annealed WO-N films displayed nvalues of $\sim 2.2$ at low nitrogen flow rates and reduced to $\sim 2.0$ with increasing nitrogen flow values then increase after a nitrogen flow rate of $13 \mathrm{sccm}$. Values for $k$, corresponding to annealed W-O-N films, increase from $\sim 0$ to $\sim 0.2$ as a function of nitrogen flow rate. It is evident that thermal treatment strongly influence the optical behavior and optical constants $(n$ and $k$ ) of W-O-N films, while nitrogen content during deposition is also an influential factor contributing to the degree or extent of overall changes in the optical characteristics. The values of $n$ steadily decrease with increasing nitrogen flow while $k$ values increase at the same nitrogen flow rates. The change in magnitude for the $n$ and $k$ values corroborate well with the change in their dispersion profiles, providing evidence thatthe thermal treatment altered the physical and electro-optical states of W-O-N films. 
The change in optical properties is an indicative of a transformation in the electronic structure of the films caused by a change in structure, especiallychemical composition, as a result of post-deposition thermal treatment in an atmosphere of Ar. To further understand the materials' response under thermal annealing, XPSmeasurements were used to determine any change in the relative contents of $\mathrm{N}$ and $\mathrm{O}$ which would indicate changes in the amount of W-N and $\mathrm{W}-\mathrm{O}$ bonds within the W-O-N films. Figures 4 and 5 present the comparison of nitrogen and oxygen contents in W-O-N films prior to and after subjected to post-depositionthermal treatment with a flow of Ar, respectively. The data is presented as a function of variable nitrogen gas flow rate.By the inspection of $\mathrm{N} 1 \mathrm{~s}$ and $\mathrm{O}$ 1s peak area evolution, it is evident that the thermal treatment causes the loss of oxygen and nitrogen in the films.

The loss of nitrogen and oxygen upon annealing in Ar atmosphere was also noted in RBS measurements.The RBS data of annealed W-O-N samples are shown in Figure 6. Experimental RBS spectra (circles) along with simulated curves (line) were shown. The backscattered ions observed were due to various elements and their respective energy positions were as indicated with arrows for the experimental spectra. The scattering due to W, the heaviest among the elements present in either the film or substrate, occurs at higher backscattered energy as seen in Fig. 6. Similarly, peaks attributed to backscattering events from $\mathrm{Si}, \mathrm{O}$, and $\mathrm{N}$ are as shown in the RBS spectra of annealed $\mathrm{W}-\mathrm{O}-\mathrm{N}$ films (Fig. 6). The measured height and width of the respective peaks are related to the concentration and thickness distribution of $\mathrm{W}, \mathrm{O}$ and $\mathrm{N}$ atoms in the oxynitride film.Peak areas serve as a calibration check for composition and thickness since known Rutherford scattering cross section and experimental parameters can be used to calculate this height and width. The composition of the films were determined by simulating the experimental spectrum for the 
set of experimental conditions. The simulated curve was calculated using SIMNRA code [41] for the fixed set of experimental parameters: (1) incident $\mathrm{He}+$ ion energy, (2) integrated charge, (3) energy resolution of the detector, and (4) scattering geometry. It can be seen in Figure 6a that the simulated curves (solid line) calculated using the experimental parameters are in good agreement with the experimental RBS spectra. This observation indicates that film composition reasonably simulates the spectra and, hence, provides the estimate of film composition. As reported elsewhere [32], the W-O-N films grown without any nitrogen corresponds to stoichiometric $\mathrm{WO}_{3}(\mathrm{~W}: 25 \%$ and $0: 75 \%)$. For as-deposited W-O-N films, as reported previously $[32,33]$, the chemical composition i.e., $x$ and $y$ in $\mathrm{WO}_{\mathrm{x}} \mathrm{N}_{\mathrm{y}}$, follows the sequence of $\mathrm{WO}_{3} \rightarrow \mathrm{WO}_{2.20} \mathrm{~N}_{0.80}$ with increasing nitrogen flow rate. Corroborating with XPS analyses, RBS measurements also indicate loss of nitrogen and oxygen in the W-O-N films annealed under Ar atmosphere. While RBS data confirms both nitrogen and oxygen loss, the average ratio of nitrogen to oxygen was changed although the change is not significant for samples grown under nitrogen flow rates in the intermediate range of 5-13 sccm. The chemical loss is more dominant at the end members, where the incorporation of nitrogen is effective as well as the samples containing the highest amount of nitrogen. As noted in Fig. 6b, the samples grown without any oxygen suffered even interdiffusion. It is noted that $\mathrm{Si}$ step edge slightly moves forward while $\mathrm{W}$ peak experiences a slight modification towards high-energy end of the peak. These two changes, as indicated by arrows in their respective directions, clearly indicate that there is some degree of intermixing of Si from the underlying substrate and $\mathrm{W}$ in the films. Thus, the chemical analyses made using XPS and RBS measurements indicate that the W-O-N films undergo a substantial chemical composition change upon annealing in Ar atmosphere at 
$400{ }^{\circ} \mathbf{C}$. However, chemical composition alone is not accounted as the primary factor that can affect the optical behavior of thin films. Especially, index of refraction values are sensitive to changes in the material density, molecular polarizability or both simultaneously. In order to account for these changes the optical properties were considered to model the changes in physical density of the W-O-N films. The density for the films was calculated using the LorentzLorenz relation $[\mathbf{1 4}, \mathbf{4 6}]$ :

$$
\frac{\rho_{f}}{\rho_{b}}=\left[\frac{\left(n_{f}-1\right)^{2}}{\left(n_{f}+1\right)^{2}} \cdot \frac{\left(n_{b}+1\right)^{2}}{\left(n_{b}-1\right)^{2}}\right]
$$

where $\rho_{f}$ and $\rho_{b}$ are the densities of the deposited films and bulk material, respectively, $n_{f}$ corresponds to the refractive index of the annealed or as-deposited $\mathrm{W}-\mathrm{O}-\mathrm{N}$ films and $\mathrm{n}_{\mathrm{b}}$ is the is the refractive index for bulk W-O-N. Bulk values for both density and refractive index were calculated using the rule of mixtures. Using the chemical compositions presented in a previous publication [32] the fraction of $\mathrm{W}-\mathrm{O}$ and $\mathrm{W}-\mathrm{N}$ bonds in each film was used to estimate bulk values. New values for bulk W-O-N were calculated using the index of refraction for bulk $\mathrm{WO}_{3}$ and $\mathrm{WN}$, at $\sim 633 \mathrm{~nm}$, to be 2.0 [47] and $3.8[48,49]$, respectively, and their bulk densities to be $7.16 \mathrm{~g} / \mathrm{cm}^{3}[18]$ and $17.7 \mathrm{~g} / \mathrm{cm}^{3}$ [50], respectively. Thus, using the $n$ values obtained from SE for both annealed and as-deposited W-O-N films, the density values are calculated. The effect of post-depositionannealing, under the flow of Ar,on the density of $\mathrm{W}-\mathrm{O}-\mathrm{N}$ films is presented in Figure 7. Density values for annealed W-O-N filmsrange from $9.1 \mathrm{~g} / \mathrm{cm}^{3}$ for lower nitrogen flows and eventually reduce to $6.1 \mathrm{~g} / \mathrm{cm}^{3}$ before climbing again after $13 \mathrm{sccm}$ of nitrogen flow.A reduction of film-density is seen as a function of nitrogen flow rate and correlates with the change in refractive index seen due to thermal annealing. Interestingly, the changes in these 
values can also be related to the change in oxygen and nitrogen contents as evident in the XPS data.

Additional optical characterization has been performed on the samples annealed in an inert atmosphere. The optical transmittance spectra for annealed W-O-N films are displayed in Figure 8. Incremental changes in the spectral transmission curves can be seen as a $\mathrm{r}$ esult of nitrogen incorporation. The annealed W-O-N films show a high transparency in the measured spectral region (250-800 nm)which is an indicative of high-quality and transparent films; however, this characteristic feature is dominant only at lower nitrogen flow rates. Optical transparency drops off where incident radiation is absorbed across the band gap $\left(\mathrm{E}_{\mathrm{g}}\right)$ and assuming an electronic transition occurs between the valence and conduction bands, $E_{g}$ values can be determined[1, 3, 6, 8, $13-14,26-28,31,39]$. The Egvalues for thin films can be calculatedusing the Tauc relation:

$$
(\alpha h v)=B\left(h v-E_{g}\right)^{2}
$$

where $\alpha$ is the absorption coefficient, $\mathrm{h} v$ is the energy of the incident photon and B is the absorption edge width parameter $[3,6,14,27-29,31,39-40]$. If reflectance is assumed to be negligible, absorption coefficient values are approximated using:

$$
\alpha=-\frac{\ln (T)}{t}
$$

where $\mathrm{T}$ is the measured transmittance values and $\mathrm{t}$ is the thickness of the W-O-N films $[3,6,14$, 27, 29, 39]. Optical band gap is determined by plotting $(\alpha h v)^{1 / 2}$ vs. hv and extrapolating the linear region to zero absorption i.e., $\mathrm{h} v=0$. C alculated $\mathrm{E}_{\mathrm{g}}$ values for both annealed and asdeposited W-O-N thin films are presented in Figure 9, where it can be seen that values for 
annealed films range from $2.8 \mathrm{eV}$ to $2.1 \mathrm{eV}$ as a function of nitrogen flow. It can be also seen that the $\mathrm{E}_{\mathrm{g}}$ values are not very much affected by annealing despite optical constants and dispersion profiles demonstrating significant changes.

Due to the alteration of optical and physical properties observed thus far, changes to the mechanical properties of W-O-N thin films caused by thermal treatment were anticipated. The method developed by Oliver and Pharr was employed to calculate the mechanical characteristics, namely hardness and reduced elastic modulus. Using this method, the reduced elastic modulus $\left(E_{r}\right)$ is calculated by finding the stiffness $(S)$ of the film from the slope of the unloading curve. The relation between $\mathrm{E}_{\mathrm{r}}$ and $\mathrm{S}$ can be described using:

$$
E_{r}=\frac{\sqrt{\pi}}{2} \frac{S}{\sqrt{A}}
$$

where $\mathrm{A}$ is defined as the area of contact at peak load [51]. The mechanical properties of the films are then calculated using the known geometry and mechanical properties of the indenter. The results gathered from nano-indentation measurements for both sets of samples annealed at $400{ }^{\circ} \mathrm{C}$ are presented in Figure 10 and compared to those values obtained for as-deposited W-O$\mathrm{N}$ samples. The results for the reduced elastic modulus reveal similar trend (not shown). All sets of samples show a decreasing trend in hardness values as the amount of nitrogen flow is increased but hardness values are greater for those annealed W-O-N films, especially those samples annealed in an air (oxygen) environment. W-O-N thin films annealed in air show hardness values between 9.6 GPa and 6.7 GPa which still remain low compared to the literature [36-38] but are significantly improved over the as-deposited samples. This increase in hardness corresponds well with previous results showing similar improvements to W-O-N films due to post-deposition thermal treatment [37]. 
Grazing incidence X-ray diffraction (GIXRD) patterns for W-O-N films annealed in an inert atmosphere (not shown) did not indicate any significant changes or peaks. This observation indicates that the W-O-N films remain amorphous even after annealing at $400{ }^{\circ} \mathrm{C}$ in an inert atmosphere. However, significant changes were seen when the W-O-N films are annealed in the presence of oxygen. Figure 11 displays the GIXRD patterns as a function of nitrogen flow rate for the W-O-N films annealed in an open atmosphere. For comparison, the XRD data of asdeposited W-O-N films deposited under variable nitrogen gas flow rates are also presented (left panel). It is evident that all the as-deposited W-O-N films are amorphous. It is evident (Fig. 11, right panel) that the samples exhibit the well-defined and resolved XRD peaks indicating thermally induced amorphous-to-crystalline transition in W-O-N films. Thepeaks correspond tothe formation of the monoclinic $\mathrm{WO}_{3}\left(\mathrm{~m}-\mathrm{WO}_{3}\right)$ phase at all nitrogen flow rates. Peaks positioned at $\sim 23.4^{\circ}$ and $\sim 24.5^{\circ}$ c orrespond to diffraction from the (002) and (200) planes, respectively, of $\mathrm{m}-\mathrm{WO}_{3}[3,46]$. However, the texturing of the films is completely different and dependent on the nitrogen flow rate employed for the deposition of W-O-N films.For a set of nitrogen flow rates up to $7 \mathrm{~s} \mathrm{ccm}$,samples exhibit anintense (200) peak indicating the preferred orientation while samples beyond this point shift to a (002) orientation. For the W-O-N film deposited with $20 \mathrm{sccm}$ of nitrogen flow, a weak peak at $\sim 36.3^{\circ}$ is observed corresponding to hexagonal tungsten nitride $(\delta-\mathrm{WN})[22,30, \mathbf{5 2}]$. The existence of this peak indicates the simultaneous existence of the $\mathrm{WO}_{3}$ and $\mathrm{WN}$ phases in $\mathrm{W}-\mathrm{O}-\mathrm{N}$ thin films deposited with high nitrogen flow rates. The formation of well-structured $\mathrm{m}-\mathrm{WO}_{3}$ phase planes correlates well with improvement of mechanical properties for W-O-N thin films annealed in an open atmosphere.

\section{Discussion}


The most notable changes seen in the properties of $\mathrm{W}-\mathrm{O}-\mathrm{N}$ films as a result of annealing are changes in the optical constantsand mechanical properties. We first focus on the changes in optical characteristics and subsequently consider the mechanical properties of annealed W-O-N films.While accounting for the observed changes through a fundamental mechanism derived based on the observed experimental results and their implications, an attempt will be made to establish a structure-chemistry-property correlation in thermally annealed W-O-N films. It is evident from the dispersion profiles of optical constants that the $n$ values for the W-O-N films annealed in an inert atmosphere become increasingly diminished (Fig. 3) as the flow of nitrogen is increased. The driving factor for this change comes from the fact that the samples annealed under a flow of Ar experience a chemical change due to the loss of nitrogen and oxygen as is evident from XPS and RBS analyses.However, nitrogen loss during Ar thermal treatment occurs at a higher rate than the loss of oxygen, changing the ratio of W-O bonds to W-N bonds and manifesting as a change in the ionic character of W-O-N films. The change in ionic character, which is heavily related to nitrogen chemistry and the optical changes of W-O-N films, occurs due to the difference in electronegativity of tungsten and oxygen (3.5) and nitrogen (3.0) atoms, respectively. Thus metal-nitrogen bonds (M-N) tend to be less ionic than metal-oxygen bonds (M-O) increasing the ionicity of Ar annealed W-O-N films due to the greater loss of nitrogen content [53]. This shift in chemical behavior also affects the overall polarizability of W-O$\mathbf{N}$ films and can be modeled as a change in the physical density due to a shift in $n$-values as modeled by the Lorentz-Lorenz relation. $T$ he density determined using spectroscopic ellipsometry (Fig. 7) clearly indicates a decrease in values for W-O-N films as a result of thermal annealing inan inert atmosphere of Ar. Mohamed and Shaaban reported that a change 
in film-density does affect $n$ values for W-O-N filmsthrough a shift in overall polarizability, as M-N bonds tend to have a higher polarity than M-O bonds[29].The same shift in ionicity seen to decrease refractive index values can be used to explain the decrease in polarizability due to the increase ratio of $\mathrm{W}-\mathrm{O}$ bonds to $\mathrm{W}-\mathrm{N}$ bonds that now exist after Ar thermal treatment.The change in chemical composition and physical density in the films can also be related to the increase seen in $k$ values. An increase in extinction coefficients is indicative of a decrease in the optical quality due to an increase defect and absorption centers [28]. Band gap values are also affected by a shift in overall ionicity as well as electronic states mixing in the valence band of a material $[40, \mathbf{5 3 - 5 5}]$. As previously stated, the band gap for semi-conducting materials exist due to electronic transitions from the top of the valence band to the conduction band. For W-O-N the valence band is formed from a intermixing of $\mathrm{N} 2 \mathrm{p}$ and $\mathrm{O} 2 \mathrm{p}$ states while the conduction band consist of empty W $5 \mathrm{~d}$ states. Additional N 2p or O $2 \mathrm{p}$ states will expand or compress the valence band and change $\mathrm{E}_{\mathrm{g}}$ values accordingly. Despite nitrogen losses occurring at a greater rate than that of oxygen, the change in the ratio between oxygen content and nitrogen content is not great enough to expand the valence band consistently and cause $\mathrm{E}_{\mathrm{g}}$ values to closer resemble those associated with stoichiometric $\mathrm{WO}_{3}$.

We now direct our attention to the effect of annealing on the mechanical properties of W-O-N films.Mechanical characterization demonstrated an improvement to the mechanical properties of W-O-N films as a r esult of annealing, despite the type of atmosphere used. It is well known that the mechanical properties of thin coatings are influences by several factors; most importantly, the microstructure, grain size, phase formation, chemical composition and internal stress.Films annealed with a flow of Ar show increased hardness values despite remaining amorphous and showing lower density values. This phenomenon 
was previously observed by Louro el al. who calculated increased hardness for W-O-N films despite a loss of nitrogen during the annealing process [37]. The increased hardness values can then be attributed to the loss of nitrogen being greater than the loss of oxygen during thermal treatment in Ar. T he greater loss of nitrogen then promotes the mobility of metallic W particles since nitrogen has been shown to act as a roadblock to the diffusion of metallic particles [56]. This in turn provides a gat eway to phase formation and grain growth, despite no discernable peaks in the GIXRD patterns of W-O-N films annealed with Ar.Also, as noted for optical properties, the tendency to become more ionic due to partial loss of constituent elements can affect the overall hardness and Young's modulus of the WO-N films upon annealing in Ar atmosphere.However, post-deposition thermal treatment in an open atmosphere exposed to oxygenoffered even greater increases in mechanical properties as presented in Figure 10. In spite of being annealed at equal temperature and duration of time, W$\mathrm{O}-\mathrm{N}$ films annealed in the presence of oxygenevidenced crystalline phase formation as can be seen in Figure 11. Thermal treatment in an open environment has been shown to cause the absorption of oxygen present in the atmosphere which is conducive to promoting oxide phase formation. Thus, at first place, the mechanical characteristics of W-O-N films annealed in oxygen atmosphere are dominantly affected by the amorphous to crystalline transformation and oxide phase formation. Studies of $\mathrm{Zn}-\mathrm{O}$ and $\mathrm{Zn}-\mathrm{O}-\mathrm{N}$ demonstrated that the thermal treatment of films in air promotes the absorption of oxygen, decreasing oxygen vacancies and defects in the films $[39, \mathbf{5 6}]$. Thus, the oxygen absorption coupled with energy provided by the temperature induces the crystallization and stability of the films leading to the formation of $\mathrm{m}-\mathrm{WO}_{3}$ phase dominant in $\mathrm{W}-\mathrm{O}-\mathrm{N}$ films. We believe stable phase formation wasvital to improving the resistance to surface deformation as documented for W-based 
materials in the literature. Dubey et al. demonstratedthat hardness values are higher for $\mathbf{Z r}-\mathbf{W}$ Nfilms with phase or multi-phase formation, than for films with an amorphous structure due to anincrease of grain boundaries to resist dislocation movements $[57,58]$. The grain size of $\mathbf{W}-\mathrm{O}-$ $\mathbf{N}$ films after thermal treatment under oxygen exposure was estimated using the standard Debye-Scherrer formula [39]:

$$
L=\frac{0.9 \lambda}{\beta \cos \theta}
$$

where $L$ is the crystallite size, $\lambda$ is the $X$-ray wavelength, $\beta$ is the full width half maximum (FWHM) of the peak in radians and $\theta$ is the angle of the peak. The average size determined is presented in Figure 12 as a function on nitrogen flow rate. To establish a correlation and for direct comparison, the variation of hardness and Young's modulus of the annealed W-O-N films is presented in the insert of Fig. 12. It can be noted that the average grain size remains high for samples with lower nitrogen flow rates but then decreases drastically when nitrogen incorporation becomes more significant in as-deposited W-O-N samples. Furthermore, the average size values (Fig. 12) are more or less constant upon oxide phase formation during thermal annealing leading to a set of mechanical characteristics dominated by the phase formation rather than size variation. Thus, the initial decrease in the hardness and Young's modulus seen might be due to the combined effect of improved crystalline quality and higher grain size [59] as noted in Fig. 12. Such, behavior was also noted in $\mathrm{Cu}$-oxide thin films as a function of growth temperature, which induced structural transformation and grain size increase leading to reduced values of hardness and Young's modulus [60]. However,at $20 \mathrm{sccm}$ nitrogen flow, the hardness and reduced Young's modulus increase to their highest values coinciding with the significant drop seen in grain size (Fig. 12). Perhaps, the effect of grain size coupled with amorphous- 
to-crystalline structural transformation may be the responsible mechanism that accounts for the observed mechanical properties in these $\mathrm{W}-\mathrm{O}-\mathrm{N}$ films. The same observation was made by Khamseh in which the author noted increased hardness for $\mathrm{W}-\mathrm{O}-\mathrm{N}$ films with the lowest grain sizes [38].The results of the mechanical characterization of annealed W-O-N films are then a prime example of improved mechanical behavior due to phase formation and microstructure as a result post-deposition thermal treatment.

\section{Conclusions}

The effect of post-deposition thermal treatment on the structure, mechanical characteristics and optical properties of $\mathrm{W}-\mathrm{O}-\mathrm{N}$ films deposited under variable nitrogen gas flow rate is evaluated.For Annealing at $400{ }^{\circ} \mathrm{C}$ in argon, dispersion profiles of $n$ and $k$ displayed a systematic change as a result of increased nitrogen flow rate. Values for $n$ and $k$ showed an alteration in magnitude as a result of thermal treatment and nitrogen flow rate. XPS analysis corroborated with the observed changes due to thermal treatment of the $\mathrm{W}-\mathrm{O}-\mathrm{N}$ films and displayed a decrease of both oxygen and nitrogen contents. Loss of oxygen and nitrogen, as evidenced in XPS and RBS analyses, leading to changes in the ionic character of W-O-N films found to be the origin of changes noted in the optical constants and mechanical properties.Density calculations provide a strong evidence the intrinsic changes in materials behavior, showing a decrease in values that supports the observed optical behavior and chemical composition changes as a result of annealing. However, optical band gap values for annealed W-O-N films under Ar atmospheredid not exhibit the same drastic changes due to the ratio of $\mathrm{W}-\mathrm{O}$ bonds to $\mathrm{W}-\mathrm{N}$ bonds remaining intact. Nano-indentation of $\mathrm{W}-\mathrm{O}-\mathrm{N}$ thin films demonstrated an improvement of mechanical properties as a result of thermal treatment, in both an inert atmosphere and an open atmosphere exposed to air. Annealed at an equal temperature of 
$400{ }^{\circ} \mathrm{C}$, the films exposed to air during thermal treatment reached the highest hardness values (9.6 GPa) for W-O-N films. The increase in hardness values for W-O-N films annealed in an open atmosphere was due to the formation of the monoclinic $\mathrm{WO}_{3}$ phase facilitated by the absorption of oxygen atoms from the environment. The dominant mechanism for improved hardness and elastic modulus in annealed films was primarily a phase formation coupled with amorphous-to-crystalline structural transformation at lower nitrogen flow rates while the effect of grain size coupled with amorphous-to-crystalline structural transformation is responsible for $\mathrm{W}-\mathrm{O}-\mathrm{N}$ films at higher nitrogen flow rates.

\section{Acknowledgements}

The authors acknowledge, with pleasure, support from the National Science Foundation (NSF) with NSF-PREM grant \# DMR-1205302. 


\section{References}

[1] S. Higashimoto, M. Sakiyama, M. Azuma, Photoelectrochemical properties of hybrid $\mathrm{WO}_{3} / \mathrm{TiO}_{2}$ electrode. Effect of structures of $\mathrm{WO}_{3}$ on charge separation behavior, Thin Solid Films. 503 (2006) 201-206.

[2] A. Karuppasamy, Electrochromism in surface modified crystalline $\mathrm{WO}_{3}$ thin films grown by reactive DC magnetron sputtering, Appl. Surf. Sci. 282 (2013) 77-83.

[3] S. Adhikari and D. Sarkar, Hydrothermal synthesis and electrochromism of $\mathrm{WO}_{3}$ nanocuboids, RSC Adv. 4 (2014) 20145-20153.

[4] H. Simchi, B.E. McCandless, T. Meng, W.N. Shafarman, Structural, optical, and surface properties of $\mathrm{WO}_{3}$ thin films for solar cells, J. Alloys Compd. 617 (2014) 609-615.

[5] C.G. Granqvist, Handbook of Inorganic Electrochromic Materials, Elsevier, New York (1995).

[6] S.K. Gullapalli, R.S. Vemuri and C.V. Ramana, Structural transformation induced changes in the optical properties of nanocrystalline tungsten oxide thin films, Appl. Phys. Lett. 96 (2010) 1-4.

[7] D. Paluselli, B. Marsen, E.L. Miller and R.E. Rocheleau, Nitrogen doping of reactively sputtered tungsten oxide films, Electrochem. Solid State Lett. 8 (2005) G301- G303.

[8] W. Li, P. Da, Y. Zhang, Y. Wang, X. Lin and X. Gong, $\mathrm{WO}_{3}$ nano flakes for enhanced photoelectrochemical conversion, ACS Nano 8 (2014) 11770-11777.

[9] Y. Xin, H. Zhou, X. Ni, Y. Pan, X. Zhang, J. Yun Zheng, S. Bao and P. Jin, The optical properties of low infrared transmittance $\mathrm{WO}_{3-x}$ nanocrystal thin films prepared by $\mathrm{DC}$ magnetron sputtering under different oxygen ratios, RSC Adv. 5 (2015) 57757-57763. 
[10] B. Hui, D. Wu, Q. Huang, L. Cai, G. Li, J. Li and G. Zhao, Photoresponsive and wetting performances of sheet-like nanostructures of tungsten trioxide thin films grown on wood surfaces, RSC Adv. 5 (2015) 73566-73573.

[11] Y. Sun, C. J. Murphy, K.R. Reyes-Gil, E. A. Reyes-Garcia,J.M. Thornton, N.A. Morris and D. Raftery, Photoelectrochemical and structural characterization of carbon-doped $\mathrm{WO}_{3}$ films prepared via spray pyrolysis, Int. J. Hydrogen Energy 34 (2009) 8476-8484.

[12] B. Marsen, E. L. Miller, D. Paluselli and R.E. Rocheleau, Progress in sputtered tungsten trioxide for photelectrode applications, Int. J. Hydrogen Energy 32 (2007) 3110-3115.

[13] A. Karuppasamy and A. Subrahmanyam, Studies on electrochromic smart windows based on titanium doped $\mathrm{WO}_{3}$ thin films, Thin Solid Films. 516 (2007) 175-178.

[14] C.V. Ramana, G. Baghmar and E.J. Rubio, M.J. Hernandez, Optical constants of amorphous, transparent titanium-doped tungsten oxide thin films, ACS Appl. Mater. Interfaces. 5 (2013) 4659-4666.

[15] M.V. Limaye, J.S. Chen, S. B. Singh, Y.C. Shao, Y. F. Wang, C.W. Pao, H.M. Tsai, J.F. Lee, H.J. Lin, J.W. Chiou, M.C. Yang, W.T. Wu, J.S. Chen, J.J. Wu, M.H. Tsai and W.F. Pong, Correlation between electrochromism and electronic structures of tungsten oxide films, RSC Adv. 4 (2014) 5036-5045.

[16] N.M.G. Parreira, N.J.M. Carvalho, A. Cavaleiro, Synthesis, structural and mechanical characterization of sputtered tungsten oxide coatings, Thin Solid Films. 510 (2006) 191196.

[17] T. Polcar, N.M.G. Parreira, A. Cavaleiro, Tungsten oxide with different oxygen contents: Sliding properties, Vacuum. 81 (2007) 1426-1429. 
[18] T. Polcar, A. Cavaleiro, Structure, mechanical properties and tribology of W-N and W-O coatings, Int. J. Refract. Met. Hard Mater. 28 (2010) 15-22.

[19] T. Yamamoto, M. Kawate, H. Hasegawa, T. Suzuki, Effects of nitrogen concentration on microstructures of $\mathrm{WN}_{\mathrm{x}}$ films synthesized by cathodic arc method, Surf. Coatings Technol. 193 (2005) 372-374.

[20] T. Polcar, N.M.G. Parreira, A. Cavaleiro, Tribological characterization of tungsten nitride coatings deposited by reactive magnetron sputtering, Wear. 262 (2007) 655-665.

[21] E.C. Samano, A. Clemente, J.A. Díaz, G. Soto, Mechanical properties optimization of tungsten nitride thin films grown by reactive sputtering and laser ablation, Vacuum. 85 (2010) 69-77.

[22] T. Polcar, N.M.G. Parreira, A. Cavaleiro, Structural and tribological characterization of tungsten nitride coatings at elevated temperature, Wear. 265 (2008) 319-326.

[23] I.N. Martev, D. a Dechev, N.P. Ivanov, T.D. Uzunov, E.P. Kashchieva, Characterization and properties of highly adhesive titanium nitride and tungsten nitride thin films, J. Phys. Conf. Ser. 113 (2008) 012025.

[24] B. Cole, B. Marsen, E. Miller, Y. Yan, B. To, K. Jones, et al., Evaluation of Nitrogen Doping of Tungsten Oxide for Photoelectrochemical Water Splitting, J. Phys. Chem. C. $112(2008) 5213-5220$.

[25] K. Nakagawa, N. Miura, S. Matsumoto, R. Nakano, H. Matsumoto, Electrochromism and Electronic Structures of Nitrogen Doped Tungsten Oxide Thin Films Prepared by RF Reactive Sputtering, Jpn. J. Appl. Phys. 47 (2008) 7230-7235.

[26] A.K. Chawla, S. Singhal, H.O. Gupta, R. Chandra, Influence of nitrogen doping on the sputter-deposited $\mathrm{WO}_{3}$ films, Thin Solid Films. 518 (2009) 1430-1433. 
[27] S.H. Mohamed and A. Anders, Structural, optical, and electrical properties of $\mathrm{WO}_{\mathrm{x}}\left(\mathrm{N}_{\mathrm{y}}\right)$ films deposited by reactive dual magnetron sputtering, Surf. Coatings Technol. 201 (2006) 2977-2983.

[28] S.H. Mohamed, A. Anders, I. Montero, L. Galán, Structural and optical evaluation of $\mathrm{WO}_{\mathrm{x}} \mathrm{N}_{\mathrm{y}}$ films deposited by $\mathrm{r}$ eactive magnetron sputtering, J. Phys. Chem. Solids. 68 (2007) 2227-2232.

[29] S.H. Mohamed, E.R. Shaaban, Investigation of the refractive index and dispersion parameters of tungsten oxynitride thin films, Mater. Chem. Phys. 121 (2010) 249-253.

[30] N.M.G. Parreira, T. Polcar, N. Martin, O. Banakh, A. Cavaleiro, Optical and Electrical Properties of W-O-N Coatings Deposited by DC Reactive Sputtering, Plasma Process. Polym. 4 (2007) S69-S75.

[31] X. Sun, Z. Liu and H. Cao, Electrochromic properties of N-doped tungsten oxide thin films prepared by reactive DC-pulsed sputtering, Thin Solid Films. 519 (2011) 30323036.

[32] O.R. Nunez, A.J. Moreno Tarango, N.R. Murphy, L.C. Phinney, K. Hossain, C. V. Ramana, Physical characterization of sputter-deposited amorphous tungsten oxynitride thin films, Thin Solid Films. 596 (2015) 160-166.

[33] O.R. Nunez, A.J. Moreno Tarango, N.R. Murphy, C.V. Ramana, Nitrogen incorporation and composition facilitated tailoring of the optical constants and dispersion energy parameters of tungsten oxynitride films, J. Alloys Compd. 683 (2016) 292-301.

[34] Y.G. Shen, Y.W. Mai, Effect of oxygen on residual stress and structural properties of tungsten nitride films grown by reactive magnetron sputtering, Mater. Sci. Eng. B. 76 (2000) 107-115. 
[35] Y.G. Shen, Y.W. Mai, Reactively sputtered $\mathrm{WO}_{\mathrm{x}} \mathrm{N}_{\mathrm{y}}$ films, J. Mater. Res. 15 (2000) $2437-$ 2445.

[36] N.M.G. Parreira, N.J.M. Carvalho, F. Vaz, A. Cavaleiro, Mechanical evaluation of unbiased $\mathrm{W}-\mathrm{O}-\mathrm{N}$ coatings deposited by d.c. reactive magnetron sputtering, Surf. Coatings Technol. 200 (2006) 6511-6516.

[37] C. Louro, J.C. Oliveira, A. Cavaleiro, Effects of O addition on the thermal behaviour of hard W-N sputtered coatings, Vacuum. 83 (2009) 1224-1227.

[38] S. Khamseh, Synthesis and characterization of tungsten oxynitride films deposited by reactive magnetron sputtering, J. Alloys Compd. 611 (2014) 249-252.

[39] J.P. Zhang, L.D. Zhang, L.Q. Zhu, Y. Zhang, M. Liu, X.J. Wang, et al., Characterization of $\mathrm{ZnO}: \mathrm{N}$ films prepared by a nnealing sputtered zinc oxynitride films at different temperatures, J. Appl. Phys. 102 (2007) 114903.

[40] J.H. Hsieh, C.C. Chang, J.S. Cherng, F.Y. Hsu, Optical properties and hydrophilic behaviors of $\mathrm{TaO}_{\mathrm{x}} \mathrm{N}_{\mathrm{y}}$ thin films with and without rapid thermal annealing, Thin Solid Films. 517 (2009) 4711-4714.

[41] SIMNRA is a Microsoft Windows program for the simulation of backscattering spectra for ion beam analysis with $\mathrm{MeV}$ ions. Additional details can be found in: Mayer, M. SIMNRA User's Guide, Technical Report IPP 9/113, Max- Planck-Institut fur Plasmaphysik, Garching, Germany, (1997).

[42] S.S. Kumar, E.J. Rubio, M. Noor-A-Alam, G. Martinez, S. Manandhar, V., Shutthanandan, S. Thevuthasan and C.V. Ramana, Structure, morphology, and optical properties of amorphous and nanocrystalline gallium oxide thin films, J. Phys. Chem. C117 (2013) 4194-4200. 
[43] J.A. Woollam Co., Inc., Guide to Using WVASE32 Spectroscopic Ellipsometry Data Acquisition and Analysis Software (2008).

[44] G.E. Jellison, Jr., Spectroscopic ellipsometry data analysis: measured versus calculated quantities, Thin Solid Films 313-314 (1998) 33-39.

[45] H. Fujiwara, Spectroscopic Ellipsometry: Principles and Applications (John Wiley \& Sons Inc.) (2007).

[46] M. Vargas, E.J. Rubio, A. Gutierrez and C.V. Ramana, Spectroscopic ellipsometry determination of the optical constants of titanium doped tungsten oxide thing films, J. Appl. Phys. 115 (2014) 1335111.

[47] K. Hong, K. Kim, S. Kim, I. Lee, H. Cho, S. Yoo, H.W. Choi, N.-Y. Lee, Y.-H. Tak and J.-L. Lee, Optical Properties of $\mathrm{WO}_{3} / \mathrm{Ag} / \mathrm{WO}_{3}$ Multilayer As Transparent Cathode in Top-Emitting Organic Light Emitting Diodes, J. Phys. Chem. C 115 (2011) 3453-3459.

[48] P. Boher, P. Houdy, P. Kaikati and L.J. Van Ijzendoorn,Radio frequency sputtering of tungsten/tungsten nitride multilayers on GaAs, J. Vac. Sci. Technol. A8 (1990) 846-850.

[49] J.W. Klaus, S.J. Ferro and S.M. George,Atomically controlled growth of tungsten and tungsten nitride using sequential surface reactions, Appl. Surf. Sci 162. (2000) 479-491.

[50] Y. G. Shen and Y. W. Mai, Effect of deposition conditions on i nternal stresses and microstructure of reactively sputtered tungsten nitride film, Surf. Coat. Technol. 127 (2000) 239-246.

[51] W.C. Oliver, G.M. Pharr, An improved technique for determining hardness and elastic modulus using load and displacement sensing indentation experiments, J. Mater. Res. 7 (1992) 1564-1583. 
[52] S. Bystrova, A.A.I. Aarnink, J. Holleman, R.A.M. Wolters, Atomic Layer Deposition of $\mathrm{W}_{1.5} \mathrm{~N}$ Barrier Films for Cu Metallization, J. Electrochem. Soc. 152 (2005) G522-G527.

[53] M. Futsuhara, K. Yoshioka, O. Takai, Optical properties of zinc oxynitride thin films, Thin Solid Films. 317 (1998) 322-325.

[54] X. Yang, C. Li, B. Yang, W. Wang, Y. Qian, Optical properties of titanium oxynitride nanocrystals synthesized via a thermal liquid-solid metathesis reaction, Chem. Phys. Lett. 383 (2004) 502-506.

[55] H. Le Dréo, O. Banakh, H. Keppner, P.-A. Steinmann, D. Briand, N.F. de Rooij, Optical, electrical and mechanical properties of the tantalum oxynitride thin films deposited by pulsing reactive gas sputtering, Thin Solid Films 515 (2006) 952-956.

[56] F.K. Shan, G.X. Liu, W.J. Lee, G.H. Lee, I.S. Kim, B.C. Shin, Aging effect and origin of deep-level emission in $\mathrm{ZnO}$ thin film deposited by pulsed laser deposition, Appl. Phys. Lett. 86 (2005) 1-3.

[57] P. Dubey, V. Arya, S. Srivastava, D. Singh, R. Chandra, Effect of nitrogen flow rate on structural and mechanical properties of Zirconium Tungsten Nitride $(\mathrm{Zr}-\mathrm{W}-\mathrm{N})$ coatings deposited by magnetron sputtering, Surf. Coatings Technol. 236 (2013) 182-187.

[58] P. Dubey, V. Dave, S. Srivastava, D. Singh, R. Chandra, Study of thermal stability and mechanical properties of amorphous $\mathrm{Zr}_{19} \mathrm{~W}_{18} \mathrm{~N}_{63}$ coatings deposited by DC/RF reactive magnetron sputtering, Surf. Coatings Technol. 237 (2013) 205-211.

[59] P. Delobelle, O. Guillon, E. Fribourg-Blanc, C. Soyer, E. Cattan, D. Rèminens, True Young modulus of $\mathrm{Pb}(\mathrm{Zr}, \mathrm{Ti}) \mathrm{O}_{3}$ films measured by nanoindentation. Appl. Phys. Lett. 85 (2004) 5185-5187. 
[60] S.-R. Jian, G. -J. Chen, W. -M. Hsu, Mechanical properties of Cu2O thin films by nanoindentation, Materials 6 (2013) 4505-4513. 


\section{Figure Captions}

Figure 1. The spectral dependence of $n$ for $\mathrm{W}-\mathrm{O}-\mathrm{N}$ films annealed in $\mathrm{Ar}$ at $400{ }^{\circ} \mathrm{C}$ for 1 hour, at various nitrogen flow rates.

Figure 2. The spectral dependence of $k$ for $\mathrm{W}-\mathrm{O}-\mathrm{N}$ films annealed in $\mathrm{Ar}$ at $400{ }^{\circ} \mathrm{C}$ for 1 hour, at various nitrogen flow rates.

Figure 3. Refractive index (n) and Extinction coefficient (k) plots for W-O-N films annealed in $\mathrm{Ar}$ at $400^{\circ} \mathrm{C}$ for 1 hour, as a function of nitrogen flow rate. Displayed is the alteration of $\mathrm{n}$ and $\mathrm{k}$ values as a result of thermal treatment compared to values obtained for as-deposited films.

Figure 4. $\quad \mathrm{N}$ 1s peak area evolution for both annealed and as-deposited W-O-N films at variable nitrogen flow rates, obtained from high resolution XPS spectra. A nnealed at a temperature of $400^{\circ}$ for 1 hour, annealed W-O-N samples display a loss in nitrogen content.

Figure 5. $\quad \mathrm{O}$ 1s peak area evolution for both annealed and as-deposited W-O-N films at variable nitrogen flow rates, obtained from high resolution XPS spectra. A nnealed at a temperature of $400^{\circ}$ for 1 hour, annealed W-O-N samples display a loss in nitrogen content.

Figure 6. RBS data of annealed W-O-N films. (a) W-O-N films deposited at 9 sccm and (b) W-O-N films deposited at the highest nitrogen content. 
Figure 7. Film-density of annealed and as-deposited W-O-N films as a function of nitrogen flow rate. Films annealed in an inert atmosphere at $400{ }^{\circ} \mathrm{C}$ for 1 hour display a loss of density due to thermal treatment.

Figure 8. Spectral transmittance curves of W-O-N films annealed in $\mathrm{Ar}$ at $400{ }^{\circ} \mathbf{C}$ for $\mathbf{1}$ hour, at various nitrogen flow rates.

Figure 9. $\mathrm{E}_{\mathrm{g}}$ values for annealed W-O-N films compared to as-deposited films as a function of nitrogen flow rate. $\mathrm{E}_{\mathrm{g}}$ remain virtually unchanged even after undergoing thermal treatment at $400{ }^{\circ} \mathrm{C}$ for 1 hour.

Figure 10. Hardness values, as measure by nano-indentation tests, for samples annealed in Ar and air $\left(\mathrm{O}_{2}\right)$ compared to values of as-deposited W-O-N films. The results are displayed as a function of nitrogen flow rate and thermal treated samples were annealed at $400{ }^{\circ} \mathrm{C}$ for 1 hour.

Figure 11. GIXRD patterns for W-O-N films annealed in air at $400{ }^{\circ} \mathrm{C}$ for 1 hour, at various nitrogen flow rates. Annealed films display peaks corresponding $\mathrm{m}-\mathrm{WO}_{3}$ phase and $\delta$ - WN, for the sample with $20 \mathrm{sccm}$ nitrogen flow rate. An insert is also displayed to demonstrate the amorphous character of as-deposited W-O-N films.

Figure 12. Crystallite size variation of W-O-N films annealed in oxygen. An insert of the nano-indentation results for the same set of samples is added to demonstrate an increase in mechanical properties when crystallite size sharply decreases. 
Figure 1

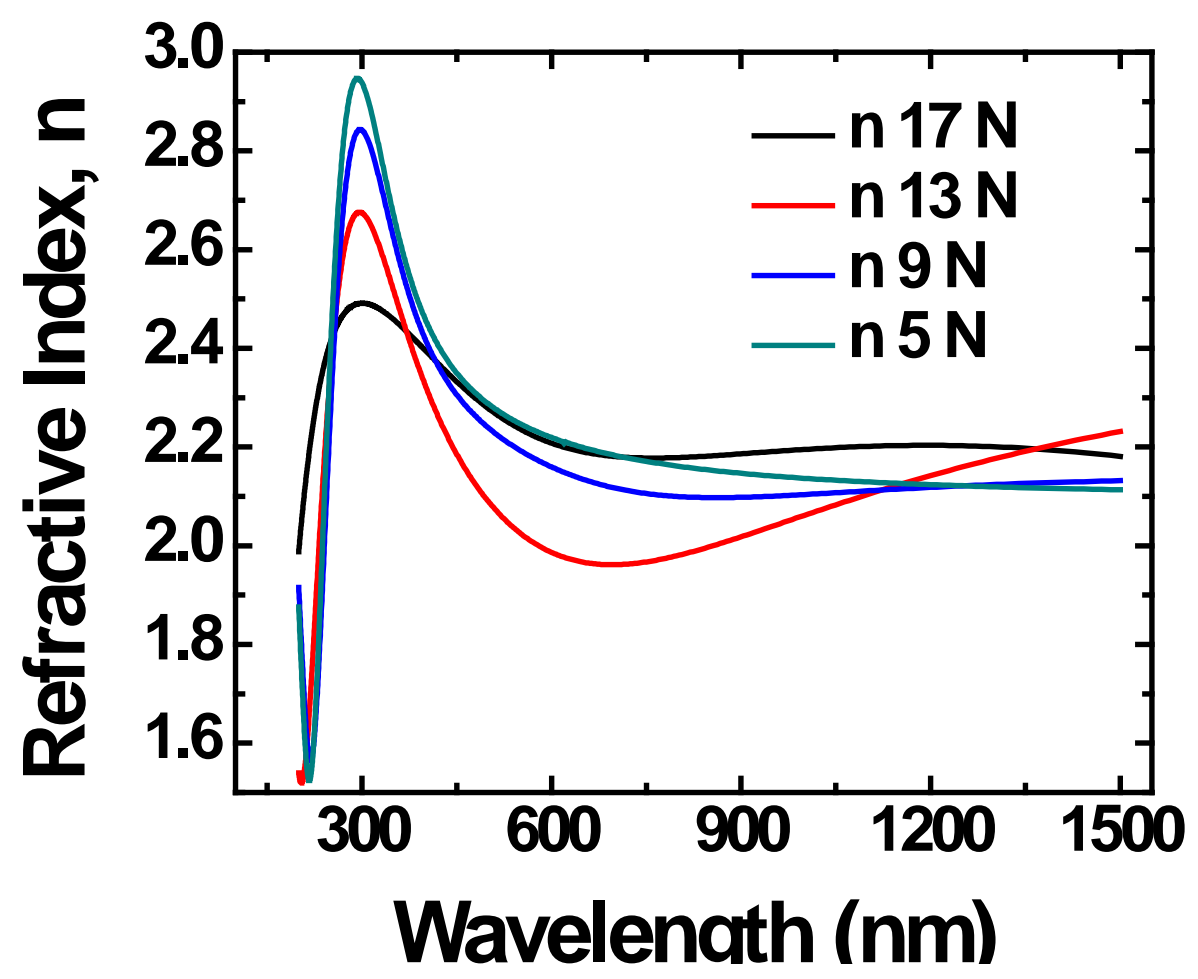


Figure 2

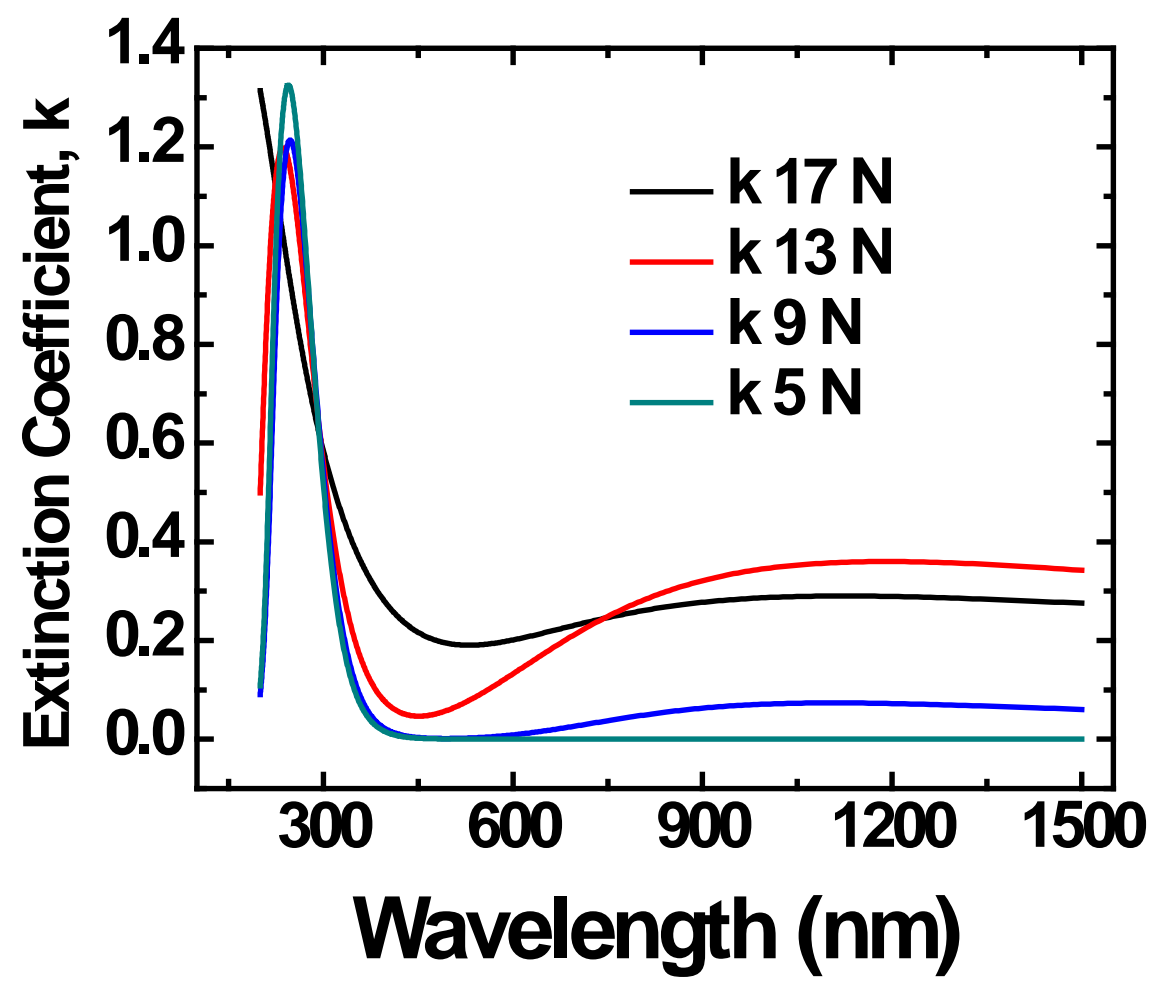


Figure 3

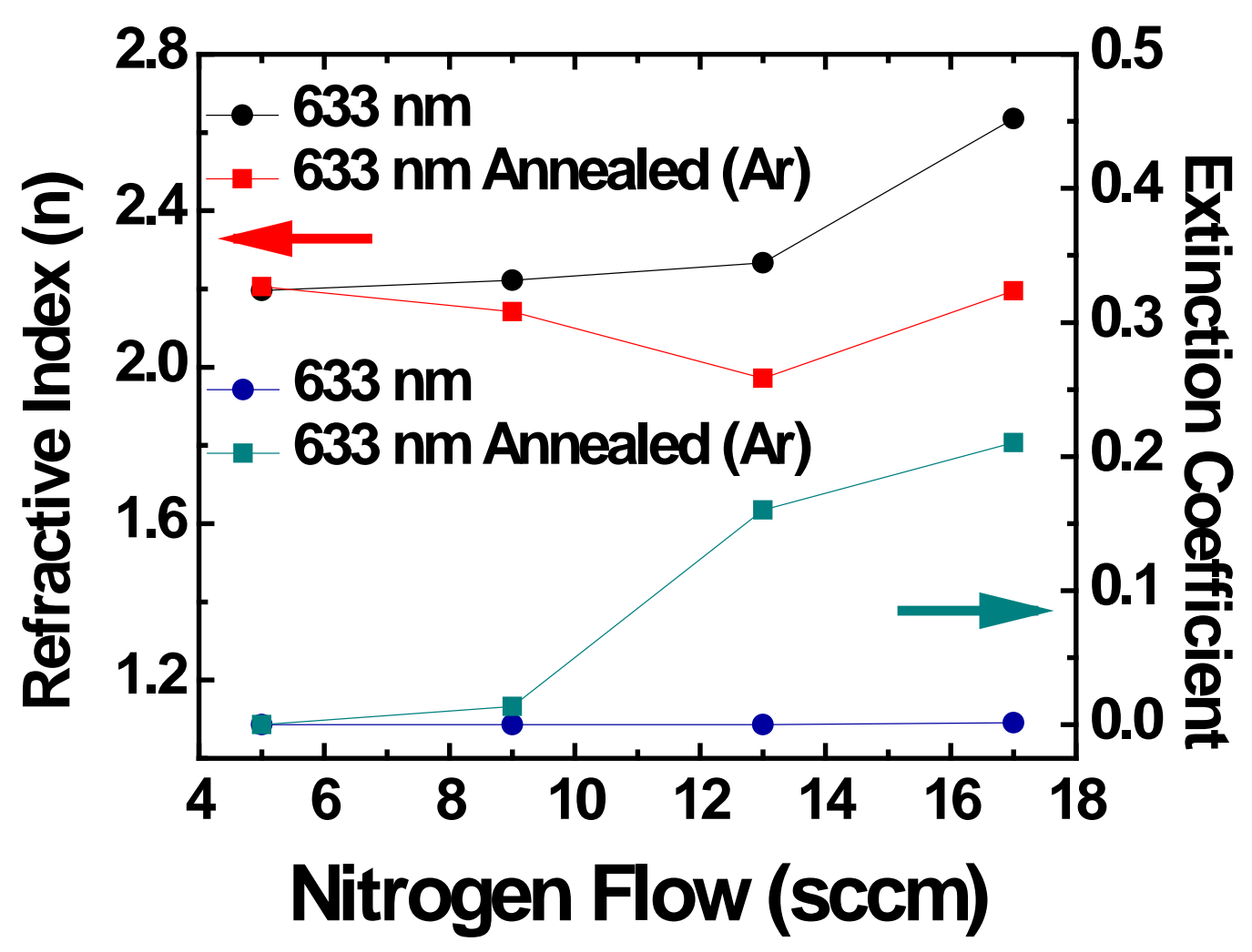


Figure 4

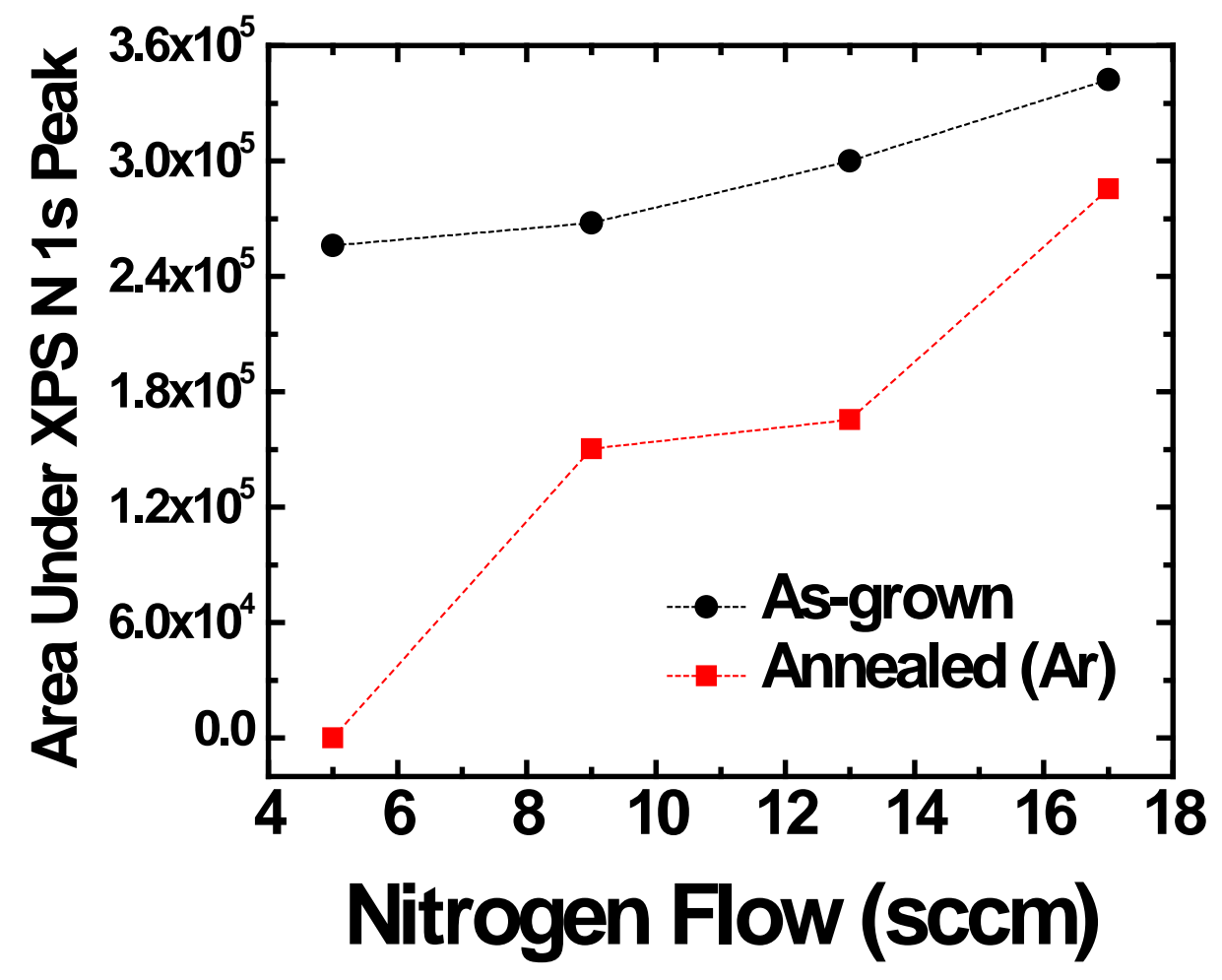


Figure 5

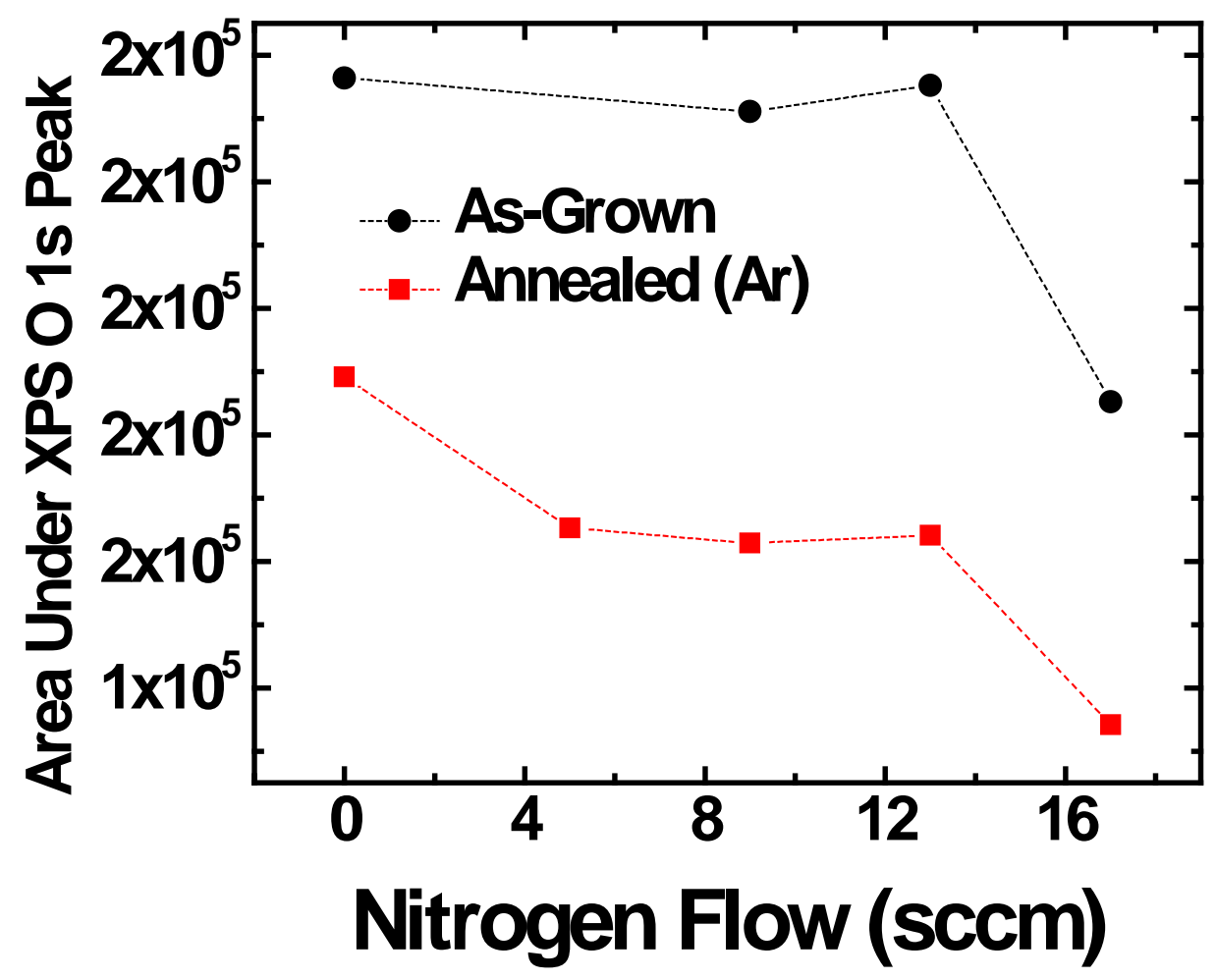


Figure 6
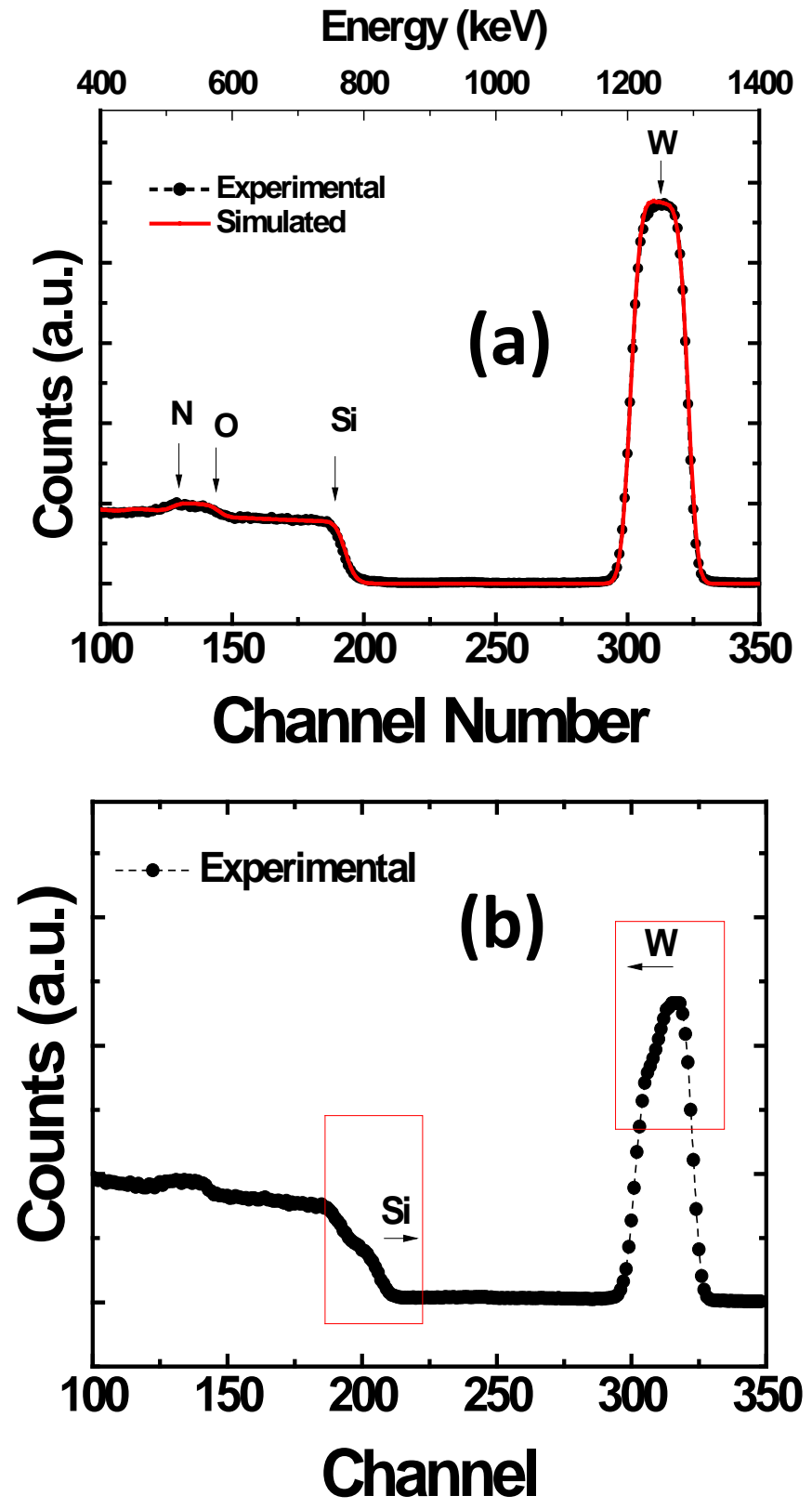
Figure 7

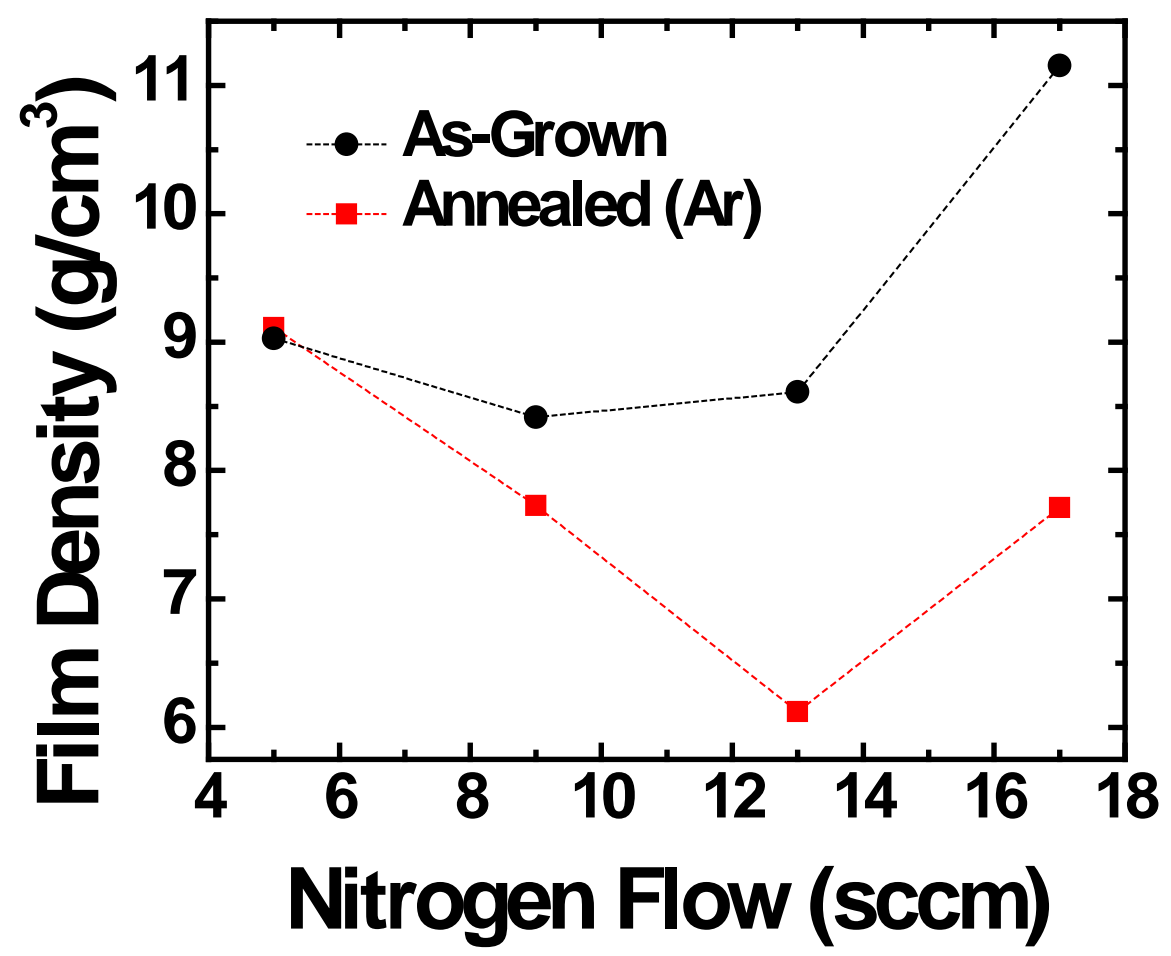


Figure 8

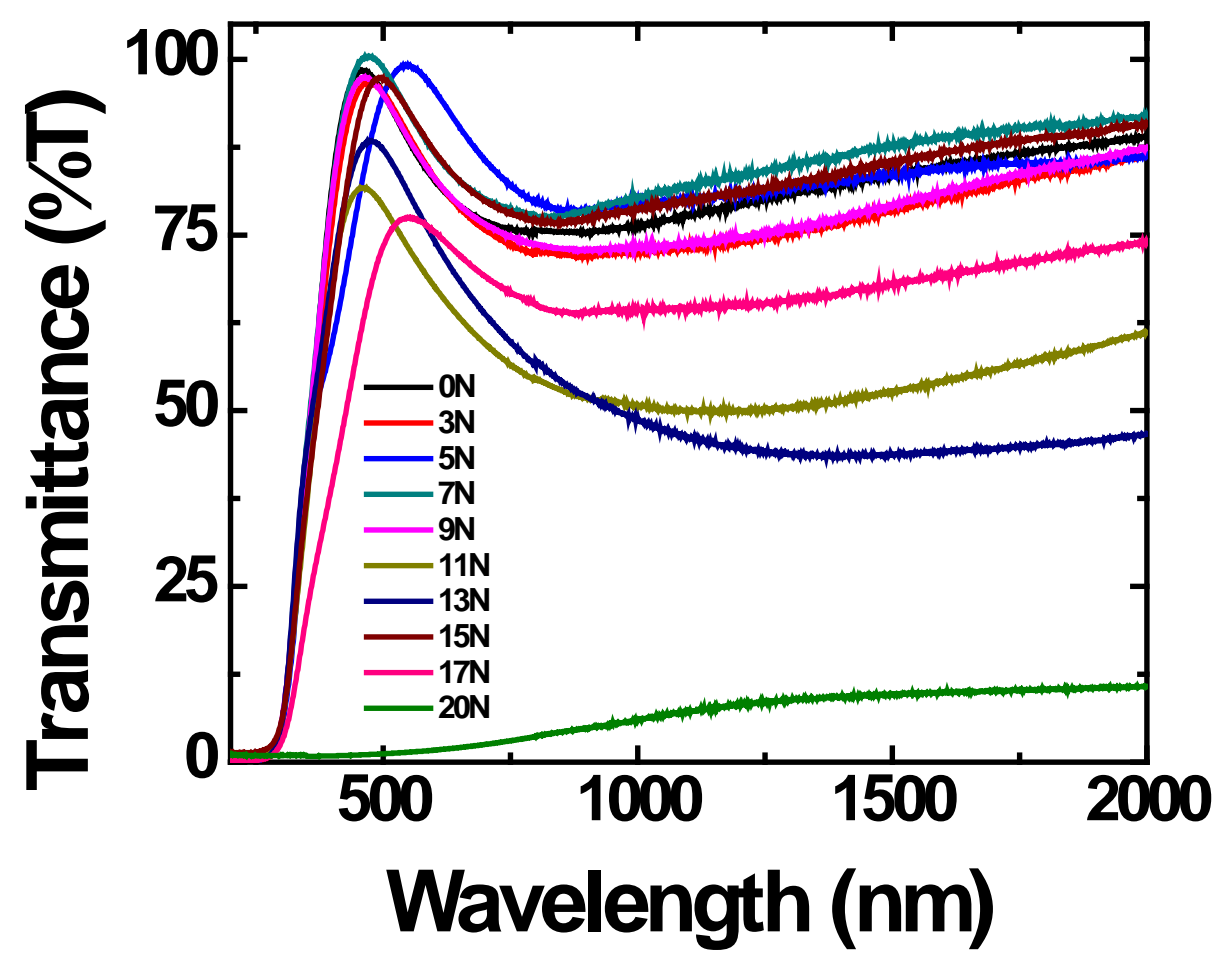


Figure 9

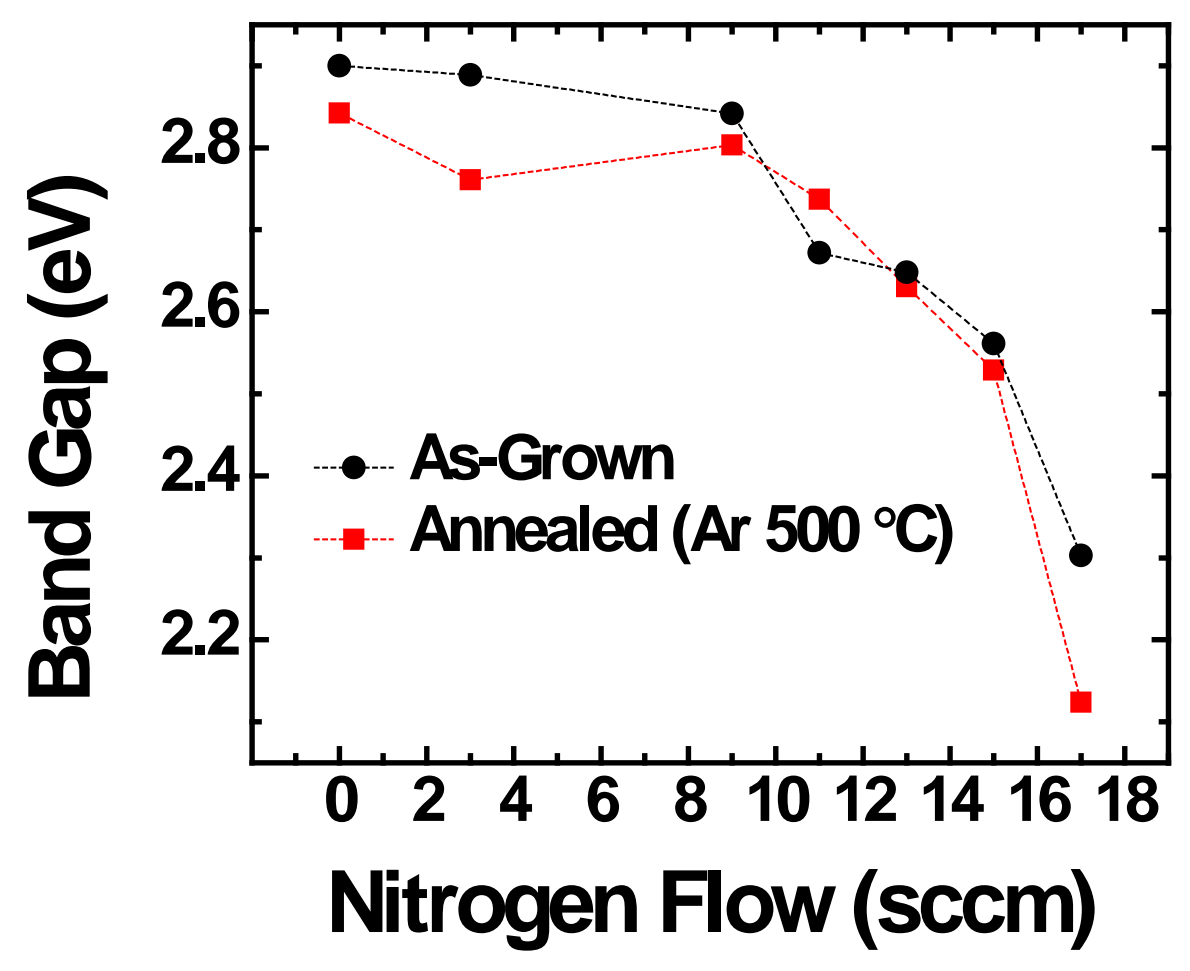


Figure 10

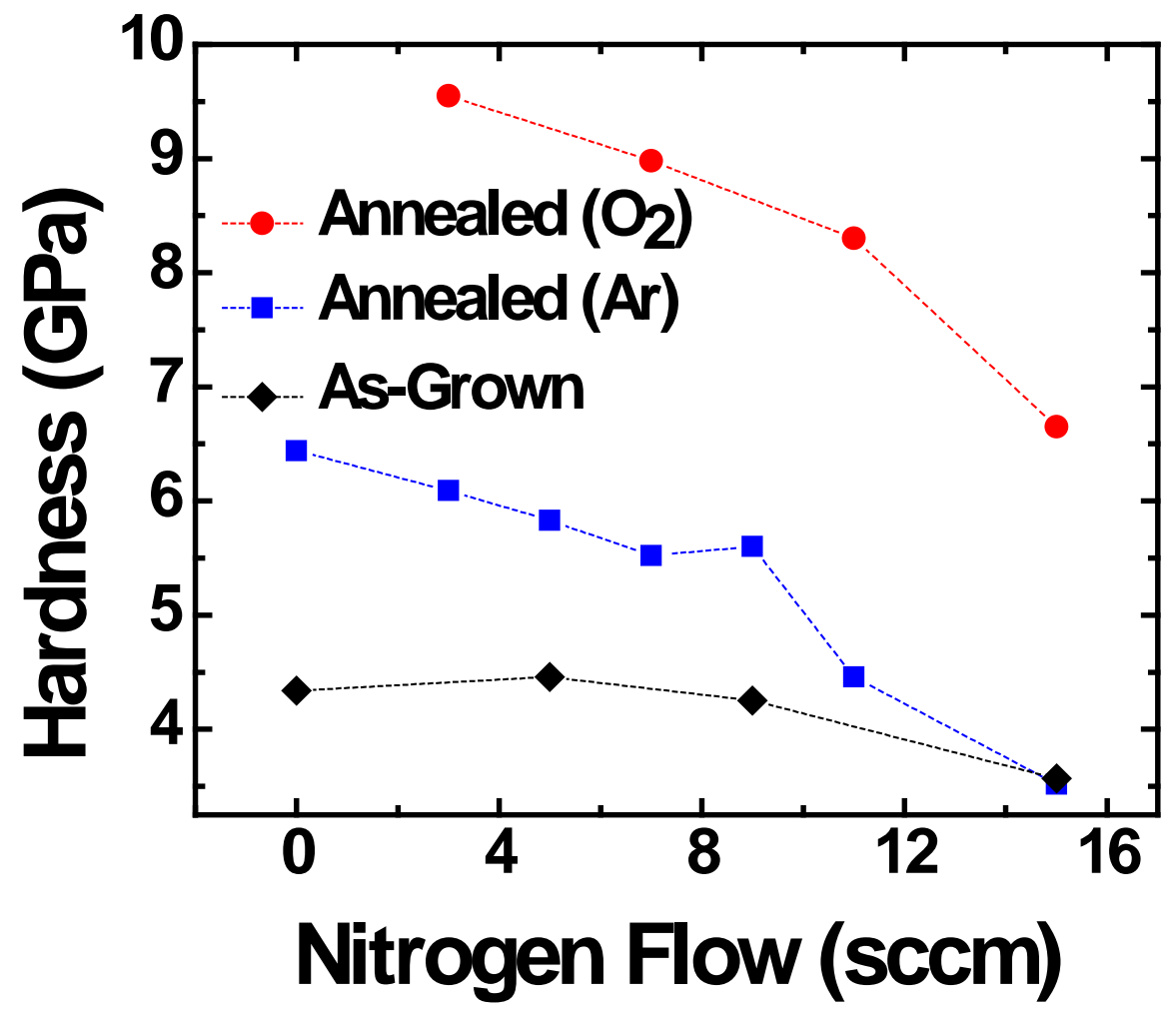


Figure 11

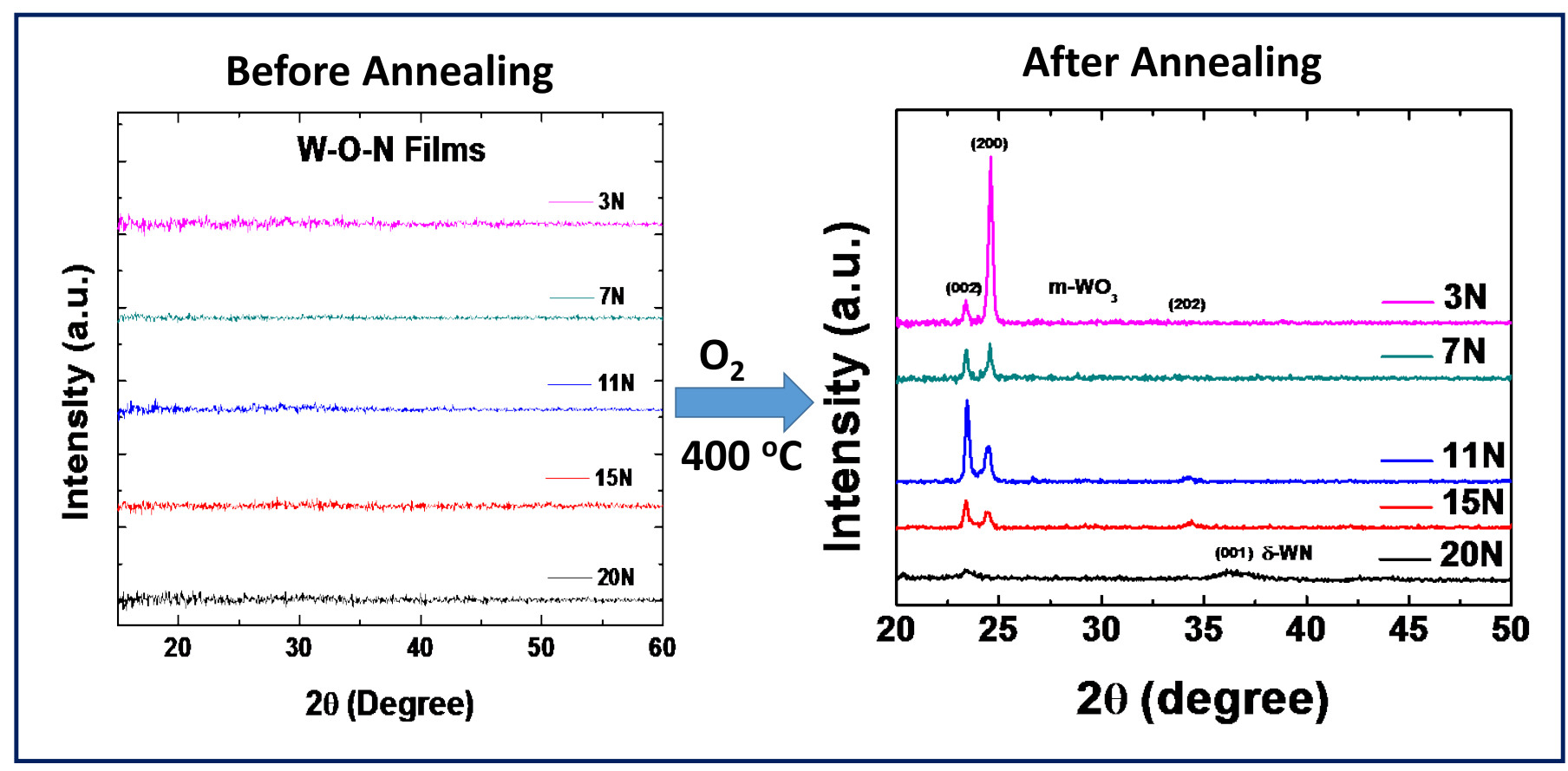


Figure 12

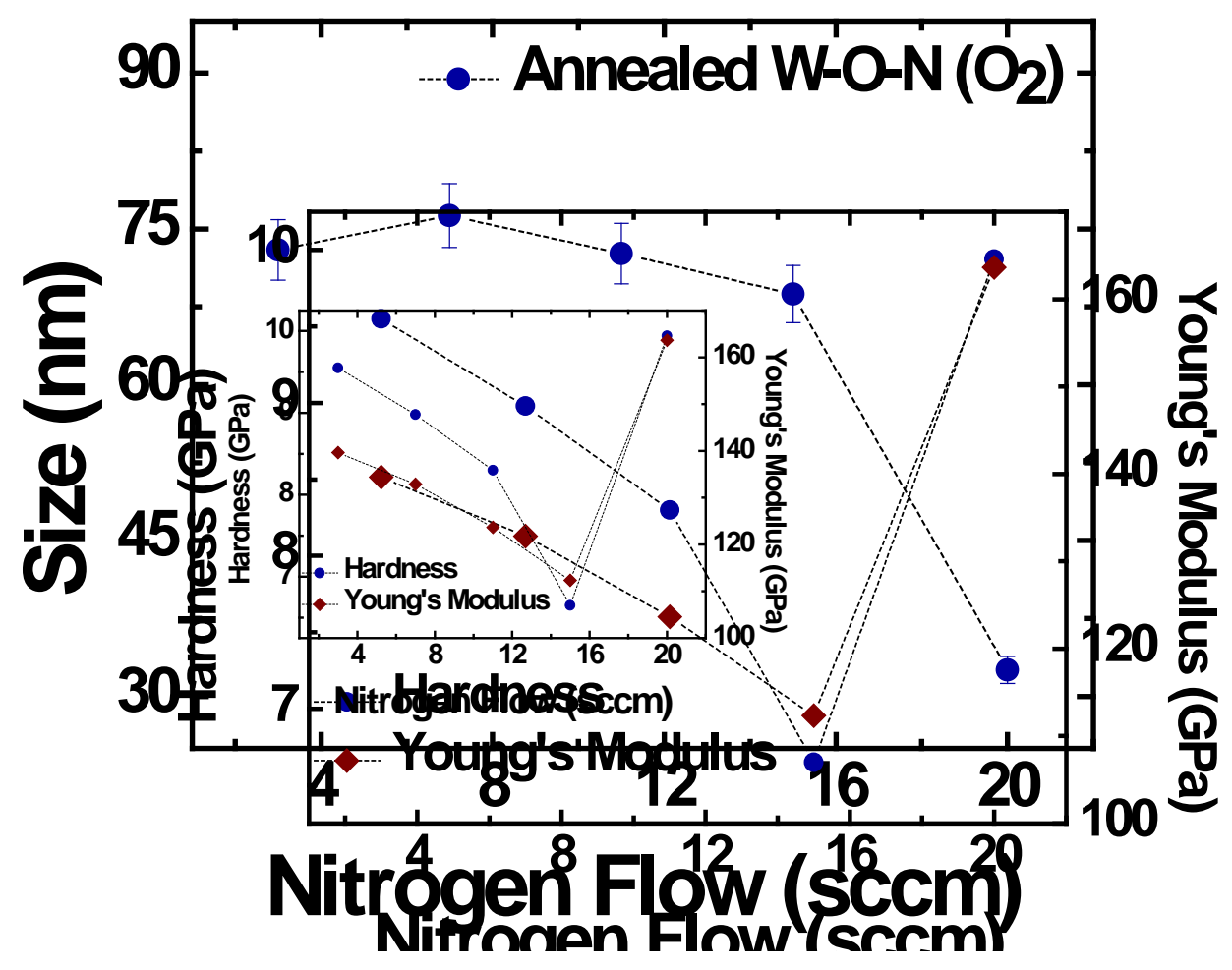




\section{Table 1}

Conditions used for the post-deposition thermal treatment of W-O-N thin films fabricated by DC sputter-deposition.

\begin{tabular}{cccc}
\hline Substrate & Temperature $\left({ }^{\circ} \mathrm{C}\right)$ & Time $($ hrs. $)$ & Atmosphere \\
\hline \hline Silicon & 400 & 1 & Argon \\
Silicon & 400 & 1 & Air \\
Quartz & 400 & 1 & Argon \\
\hline
\end{tabular}

